\title{
Cloud E-learning for Mechatronics: CLEM
}

\author{
Kuo-Ming Chao, Anne E. James, Antonios G. Nanos, Jen-Hsiang Chen \\ Distributed Systems and Modelling (DSM) Research Group \\ Faculty of Engineering and Computing \\ Coventry University, Priory Street, \\ Coventry, UK, CV1 5FB \\ \{a.james, k.chao \}@ coventry.ac.uk
}

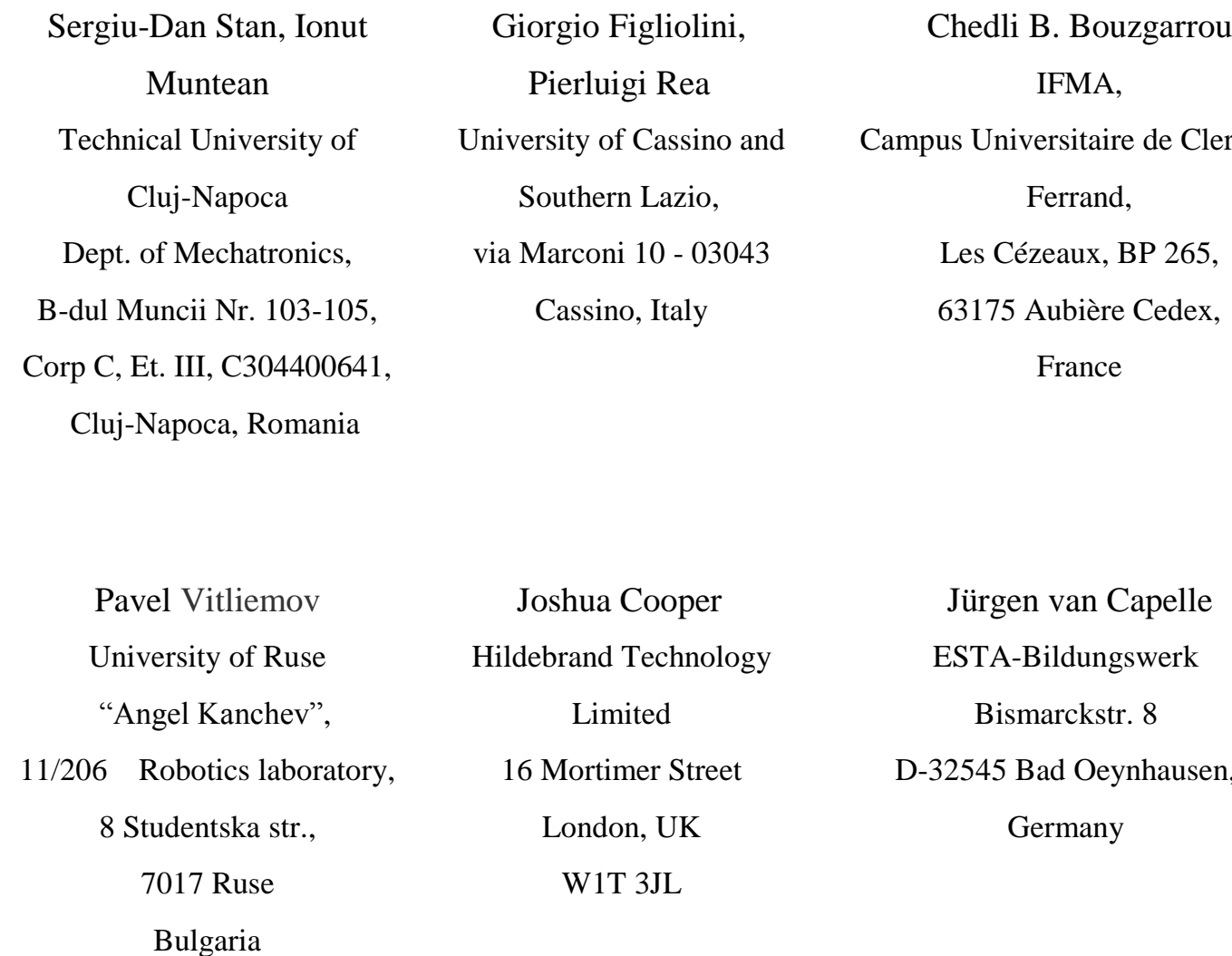

Abstract - This paper describes results of the CLEM project, Cloud E-learning for Mechatronics. CLEM is an example of a domain-specific cloud that is especially tuned to the needs of VET (Vocational, Education and Training) teachers. An interesting development has been the creation of remote laboratories in the cloud. Learners can access such laboratories to support their practical learning of mechatronics without need to set up laboratories at their own institutions. The cloud infrastructure enables multiple laboratories to come together virtually to create an ecosystem for educators and learners. From such a system, educators can pick and mix materials to create suitable courses for their students and the learners can experience different types of devices and laboratories through the cloud. The paper provides an overview of this new cloud-based e-learning approach and presents the results. The paper explains how the use of cloud computing has enabled the development of 
a new method, showing how a holistic e-learning experience can be obtained through use of static, dynamic and interactive material together with facilities for collaboration and innovation.

Keywords — mechatronics; e-learning; cloud; virtual laboratories; remote laboratories; community; ecosystem

\section{Introduction}

Mechatronics combines the disciplines of electronics, mechanics and computer science. The fusion of techniques from these disciplines enables fantastic technological advances with many practical applications. Example application areas include the medical field and increasingly intelligent industrial automation with sophisticated use made of highly-calibrated sensors and complex control systems. A workforce with relevant skills is essential if the potential of these technologies is to be realized. Highly trained individuals with relevant skills in mechatronics will be increasingly sought after by emerging industries in the new technological and information age.

Heightened by the growth and vision of the Internet of Things [1, 2], a need has been identified in Europe for vocational skills development in the area of mechatronics $[3,4,5]$. The objective of the EU Leonardo project in CLoud E-learning for Mechatronics (CLEM) is to develop an infrastructure for e-learning based on cloud services which will contribute to satisfying this need [6]. The approach of CLEM is to develop a method and exemplar to enable learning providers to create and deliver suitable courses in mechatronics, tailored to local requirements, in a scalable and sustainable way.

Training, and in particular, vocational education and training (VET) has in recent years gained an important status on the European social and political agenda. Demands for a highly skilled workforce for the European economy are challenges for the teacher and training community. Continuing professional development (CPD) of teaching staff and trainers is a key element in meeting the demands of industry for highly skilled workers. Skilled educators are needed to train the workforce. This project has resulted in an interactive resource base in mechatronics which is tuned to the needs of VET teachers and hosted in the cloud. This provides a new and dynamic method of teaching through which teachers and trainers can impart industry-ready knowledge and develop relevant skills.

The emerging technologies of cloud computing and service-oriented computing, allow resources to be interoperable and shareable. This enables the facilities and materials for e-learning to be modelled as services and managed in the cloud. The advantage of this is that the users can obtain their required services without being concerned with technical issues. In addition, teaching materials can be easily composed to meet the users' requirements. Teaching or training materials developed in this way become accessible and sharable.

Many educational programmes display a trend towards increased cooperation, not only between different departments in the same organisation but also among the many different organisations involved in national VET systems. These include schools, training institutions, companies and local and central government. Often, cooperation takes the form of what we have called bottom-across 
coordination, with individual teachers cooperating directly with teachers, researchers, administrators and policy-makers outside their own organisation. This trend is embraced in CLEM which provides the means of community building and resource sharing.

CLEM is designed to be a platform to allow e-learning resources that can be interoperable and sharable in the e-learning community, but trainers have different requirements and preferences to meet their student background and training purposes. The number of students can be various in classes or courses, so the system should be flexible to accommodate their requests by providing their required sizes or numbers of resources. In addition, the resources exist in heterogeneous forms such as hardware (e.g. CNC machines, Motors, Servo and 3D printers), programs to control the hardware, and multi-media such video clips, animation and slides due to the multi-disciplinary nature of the discipline of mechatronics. This is compounded with the dispersed locations of the resources, learners and trainers.

In this paper we describe the approach taken in order to deliver the CLEM objective and present our results. The paper is organized as follows. Section 2 reviews the state of the art in e-learning and virtual laboratories. Section 3 presents CLEM. Section 4 evaluates CLEM as a cloud platform while section 5 provides a user evaluation of the system. Section 6 analyses related literature on cloud e-learning, pointing out the innovative nature of CLEM. Section 7 concludes the paper.

\section{Related Work in E-learning}

E-learning is becoming very important in higher education as a means of reaching wider audiences as well as a convenient way to supplement traditional learning. Students like to see learning materials online as well as being presented in a classroom as it gives them more opportunity to learn and greater location freedom. Various principles for e-learning have emerged, an important one being the development of a community of inquiry [7]. A community of inquiry is the idea of groups of learners and instructors communicating or collaborating in order to increase understanding or solve a problem. This idea is better supported in e-learning rather traditional learning because of the ease with which communications can be made in an online setting. An online community of inquiry can be supported through a cloud infrastructure, which is the approach taken in CLEM. Another important development in e-learning has been the provision of virtual or remote laboratories [8].

The idea of virtual laboratories in science and engineering has prevailed for some time now, ever since computers became very networked and ubiquitous. In 1986 National Instruments launched LabView (Laboratory Virtual Instrument Engineering Workbench) which is a software platform for interfacing to laboratory instruments enabling control and visualization. Many different types of instruments and buses are available for inclusion. In 2000, Ertugrul provided a review of virtual laboratory implementations that had been created using LabView [9]. He described the basic structure of a virtual laboratory as being a device under test which can be controlled electronically. Various sensors gather data from the device. The data can be captured and analysed remotely. The 
analysis results can determine control commands which can be sent to the device via a control interface. The experimenter can decide which control instructions to send or what environmental factors to change depending feedback. The experimenter can also set hypotheses and test these to by analyzing the data that is gathered. Ertugrul's review describes industrial and education applications in various areas of engineering and science.

One of the main advantages of virtual laboratories used in education is that learners can have access to laboratory equipment and data that we would otherwise be beyond their reach, because of cost, time, distance or rarity. Ertugrul observed that the roles of teachers and students were changing and that new methods of learning were still to be discovered. Since then there has been much further effort and interest in virtual or remote laboratories in both education and industry. For instance, in 2003, Bistak and Zakova discuss organizing tele-experiments for control education [10]. The paper describes the authors' experiences in building remote laboratories. It also illustrates the various architectures for providing real experiments via the internet.

In 2005, Martin and Munoz [11] describe a distance learning course on virtual laboratory implementation for high school science teachers. The simulation environment used to implement the virtual laboratories in this case was Easy Java Simulations (Ejs), an open-source tool for teachers who do not need complex programming skills and which enables easy building of interactive visualisations based on mathematical models. The intended audience was high school teachers who wished to make use of interactive simulation in their classes. The course gives the skills to design and implement virtual laboratories for educational purposes using Ejs.

Remote control of experiments via Matlab was presented in 2006 [12] and in 2008 Zilka, Bistak and Kurcik described a hydraulic plant remote laboratory [13]. The authors discussed the means in which the hydraulic system could be integrated into a virtual laboratory. In 2009 Rojko described a system for e-training in mechatronics [14]. The system consisted of standard modules in the form of static learning material and also a virtual laboratory which was made through LabView. More recently Chaos et al. [15] have used EjS, Matlab and LabView to create virtual and remote laboratories. The Digital Systems and Media Computing (DSMC) laboratory of the Hellenic Open University (HOU) has created a web-based remote laboratory for mechatronic control using Arduino [16]. This system is similar to the approach used in CLEM but our approach to the remote lab extends this concept in terms of examples, architecture and in scalability.

In 2013, the Open University UK launched their OpenScience initiative [17]. OpenScience consists of a number of virtual laboratories accessible via the web covering various areas of science. The approach of OpenScience is recreation rather than simulation. This means that data and images recorded from experiments previously carried out by researchers is captured and used as a foundation for the virtual laboratory. The group prefers this approach because simulation and rendering of complex experiments can take massive amounts of processing time and can be error-prone. Examples of OpenScience applications are the virtual microscope through which moon dust can be viewed; a histology laboratory where samples can be analysed through a virtual microscope; a chemistry 
laboratory where reactions of chemicals in various experiments are visually reproduced; and an animal science laboratory where users can conduct experiments on rats. The applications are being used in some university classes and also could be used in schools. The OpenScience project wishes to co-opt more providers from various organizations who might wish make a virtual laboratory application available as part of the holistic system.

There are a number of other initiatives that aim to bring virtual laboratories together. The Global Online Laboratory Consortium (GOLC) focuses on promoting the development and sharing of research in remote laboratories for education [18]. Library of Labs (LiLa) was a European project which ran from 2009-2011 and involved eight universities and three companies [19]. The project aimed to provide an integrated platform for remote experiments and virtual laboratories [20]. The iLab project is an MIT based project which built on the premise that online laboratories can enrich science and engineering education [20]. The iLab project links users to remote laboratories over the Web. The architecture consists of a Lab Sever, a Lab Client and a Service Broker which mediates exchanges between the Lab Server and the Lab Client over the Web. It also provides common administrative services such as authentication and data storage. The iLab project has partners from around the world but appears not to have been active since 2011. The iLab project recognized three main types of remote experiment: batched; interactive; and monitoring. In a batched experiment, the whole experiment is defined in advance and instructions for running the experiment are sent to the system. The user has no interaction when the experiment is running. In an interactive experiment the user is able to change parameters as the experiment runs. In a monitoring experiment the user cannot change parameters while the experiments is running but can observe what is happening during the experiment course. Table I lists and summarises the three modes.

From the literature review it is evident that there is currently much interest in developing systems for distance learning which include online laboratories. There are three main approaches to on-line laboratory provision. One is recreation. This method is where experiments have already been carried out in real life and the data has been collected. In real-life, variables will have been subject to change and reactions will have been collected based on differing variable values. The experiment is then recreated almost like an on-line game so that users can interact and change experimental parameters. Different results will occur depending on the decisions of the users. This approach enables users to design and carry out an experiment within certain parameters. We can say that recreation is based on an inductive, experimental approach and is suited to scientific experimentation. Simulation is more mathematically based and is in fact often implemented via Matlab. Rules and mathematical formulae are built in which follow the principles of physics. This means that digital artefacts representing mechanical devices can be subject to varying input parameters and will behave as the real devices would behave. An advantage of simulation is that a controlled environment is assured. Thus the user is less prone to vagaries and inconvenience of unexpected mechanical or electronic failure. Actualisation ( or the remote laboratory approach) is where users actually manipulate real devices by sending messages from a remote location to the device. The advantage of this approach is that it can 
be more engaging educationally and can be developed to offer real-life remote manufacturing which could bring many economic opportunities and advantages. The CLEM approach adopts actualization and enhances this through the provision of community services. Table II shows the three main approaches to providing online laboratories and also shows the CLEM approach.

It has been recently recognized that cloud infrastructure can provide the scalability and facility for collaboration that a number of the above-described projects do not have [22, 23, 24, 25]. Through using a cloud infrastructure, more learners can be reached and larger communities can develop bringing greater ranges of knowledge and expertise. As this is a fairly new concept, there are as yet no well-embedded and, as far as the authors are aware, just a few developing systems that embrace the concept.

TABLE I: THREE TYPES OF REMOTE EXPERIMENT

\begin{tabular}{|l|ll|}
\hline Type & \multicolumn{2}{|c|}{ Characteristic } \\
\hline Batched & $\bullet$ & Whole experiment defined in advanced and instructions \\
& & sent \\
& $\bullet$ & Experiment runs without user interaction \\
\hline Interactive & $\bullet$ & User is able to change parameters as the experiment \\
& & runs \\
\hline Monitoring & $\bullet$ & Sensors are used to collect data \\
& $\bullet$ & Device is controlled automatically \\
& $\bullet$ & No interaction during experiment \\
& $\bullet$ & User simply monitors \\
\hline
\end{tabular}

TABLE II. APPROACHES FOR ONLINE LABORATORIES IN DISTANCE LEARNING

\begin{tabular}{|c|c|c|}
\hline Approach & $\begin{array}{c}\text { Example Product/ } \\
\text { Project }\end{array}$ & Characteristics \\
\hline $\begin{array}{l}\text { Recreation } \\
\text { (Virtual Lab) }\end{array}$ & OpenScience & $\begin{array}{l}\text { - } \quad \text { Data from real experiments is collected } \\
\text { - } \quad \text { Real images are collected } \\
\text { - } \quad \text { Data and images used to recreate the experiment }\end{array}$ \\
\hline $\begin{array}{l}\text { Simulation } \\
\text { (Virtual Lab) }\end{array}$ & EjS, Matlab, & $\begin{array}{l}\text { - Mathematical models provide foundation } \\
\text { - Graphics and visualisations controlled by mathematical models } \\
\text { according to user input }\end{array}$ \\
\hline $\begin{array}{l}\text { Actualisation } \\
\text { (Remote Lab) }\end{array}$ & $\begin{array}{l}\text { iLab } \\
\text { CLEM, LabView, } \\
\text { Arduino Labs at HOU }\end{array}$ & $\begin{array}{l}\text { - } \quad \text { Real Devices connected to software controllers } \\
\text { - } \quad \text { Real Devices operated by instructions provided through the software } \\
\text { - } \quad \text { Camera may be used to show device in action in real-time }\end{array}$ \\
\hline $\begin{array}{l}\text { Community } \\
\text { Support and } \\
\text { Innovation } \\
\text { (Added }\end{array}$ & CLEM & $\begin{array}{l}\text { - } \\
\text { services provided to enable uses to set up add laboratories, materials or } \\
\text { - } \quad \text { Expert channel } \\
\text { - } \quad \text { Community channel }\end{array}$ \\
\hline
\end{tabular}




\begin{tabular}{|l|l|l|}
\hline Value) & $\bullet \quad$ Facilities provided to enable users to tailor and set up courses easily \\
\hline
\end{tabular}

\section{CLEM System Overview}

The CLEM high-level architecture consists of a server which holds static learning resources, such as e-books, power point slides and lecture notes. The server also hosts Moodle which provides the Integrated Learning Environment through which the static materials can be accessed. The server also links to a number of remote laboratories and contains a booking and access system so that the laboratories can be booked and accessed by teachers or learners. Additionally the server hosts a collaborative meeting facility called CLEM ROOM so that trainers can access expert advice and also help each other as knowledge and experience grows. CLEM ROOM, which include an Expert Channel, captures the structure and protocol of a meeting to provide a better abstract representation of behavior and communication protocol between meeting participants and is based on our previous work [26, 27, 28]. Experts are registered to the system. Initially the experts are the developers of the systems and the originators of the source materials. CLEM ROOM enables teachers and trainers can see the list of experts together with their expertise. Teachers and trainers can send questions to experts and they can also book an online meeting with an expert. Experts can self-register as the community and expertise grows. Teachers and trainers can also use the virtual meeting space to communicate with each other and set up structured meetings. Fig. 1 shows the overarching architecture of CLEM. The idea is that the system will become self-sustaining through the community approach. Trainers can add their own materials and laboratories if they are prepared and able to make these public. It is also possible to build the system in a scalable way by adding links to new servers and services. Private clouds built in the same style can also be made as the CLEM approach is open and provides the method for creating such a system as well as providing an exemplar platform. We call these replica clouds. Fig. 2 shows the vision of an active community sustaining a cloud-based e-learning infrastructure in mechatronics and also illustrates the concept of a private replica cloud, which may be required by individual training organizations. The development of the system was informed by a requirements survey [29]. 


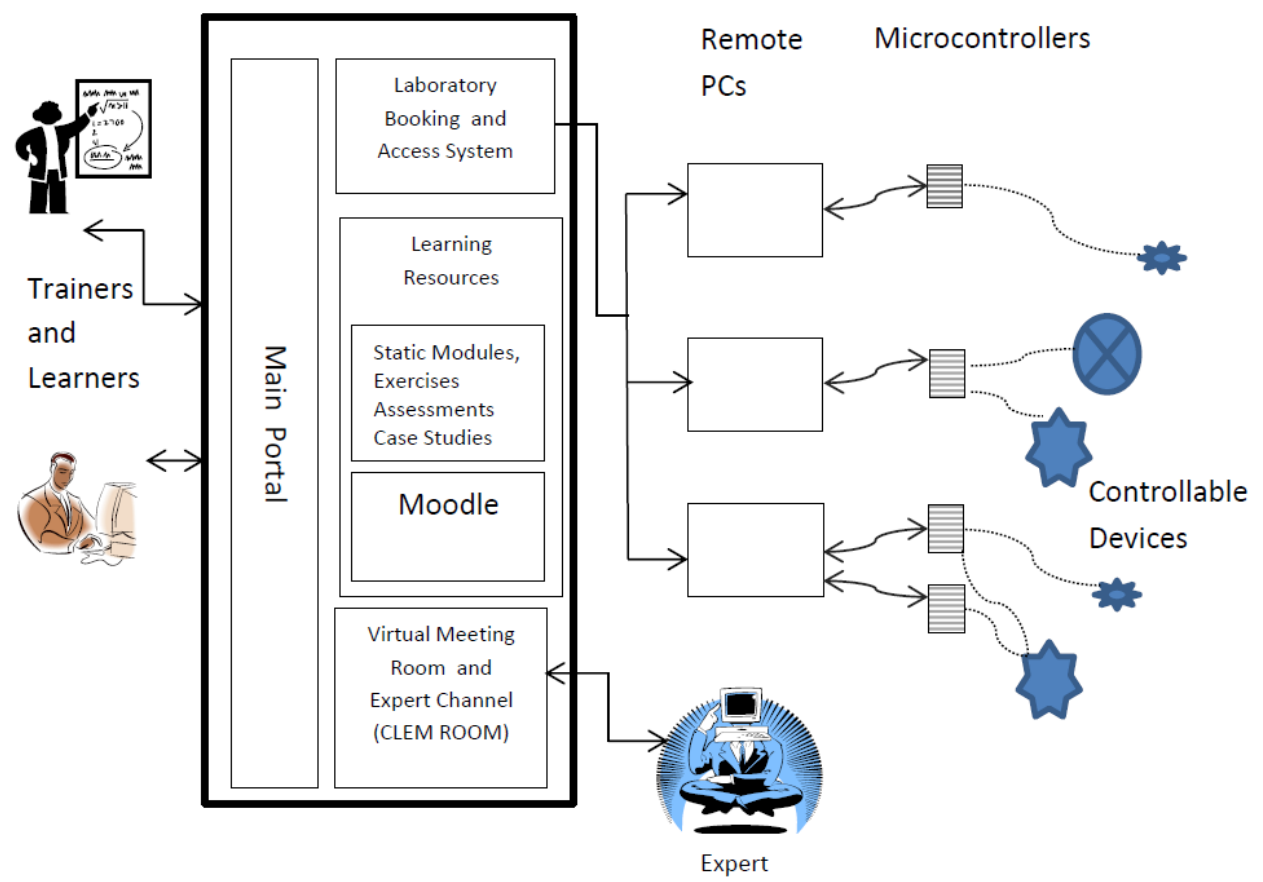

Fig.1. High-level Architecture of CLEM System 


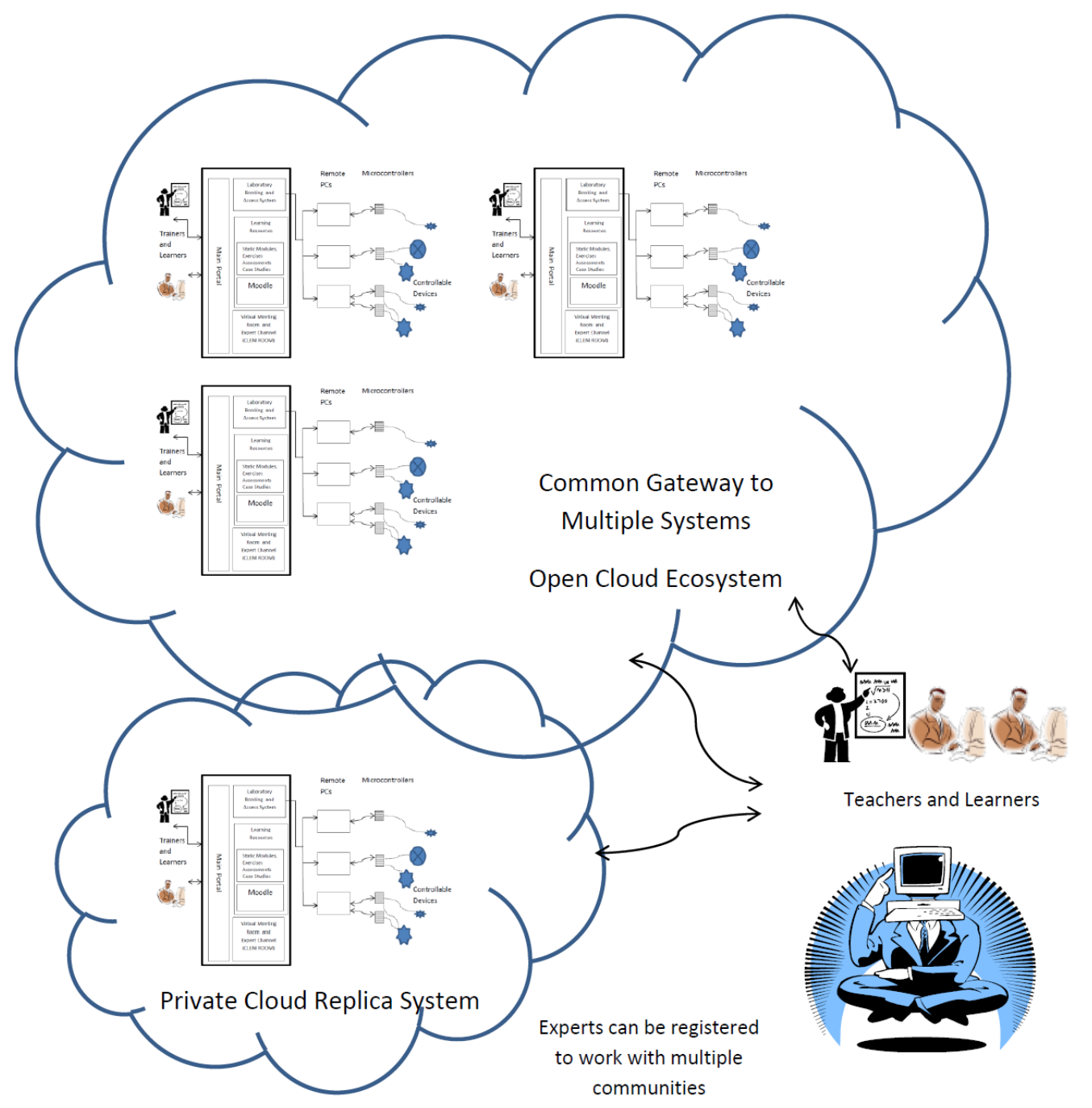

Fig. 2. The CLEM Ecosystem.

\subsection{Static Modules}

The static modules are in the form of PowerPoint slides or multimedia on relevant topics in mechatronics. Each module has meta-information associated with it giving information such as objectives, learning time and prerequisites (see Fig. 3). We used the learning environment Moodle as a platform to manage the teaching materials and courses as well as learners' progress. Initially some modules as a suitable introductory course to the topic of mechatronics were provided. 


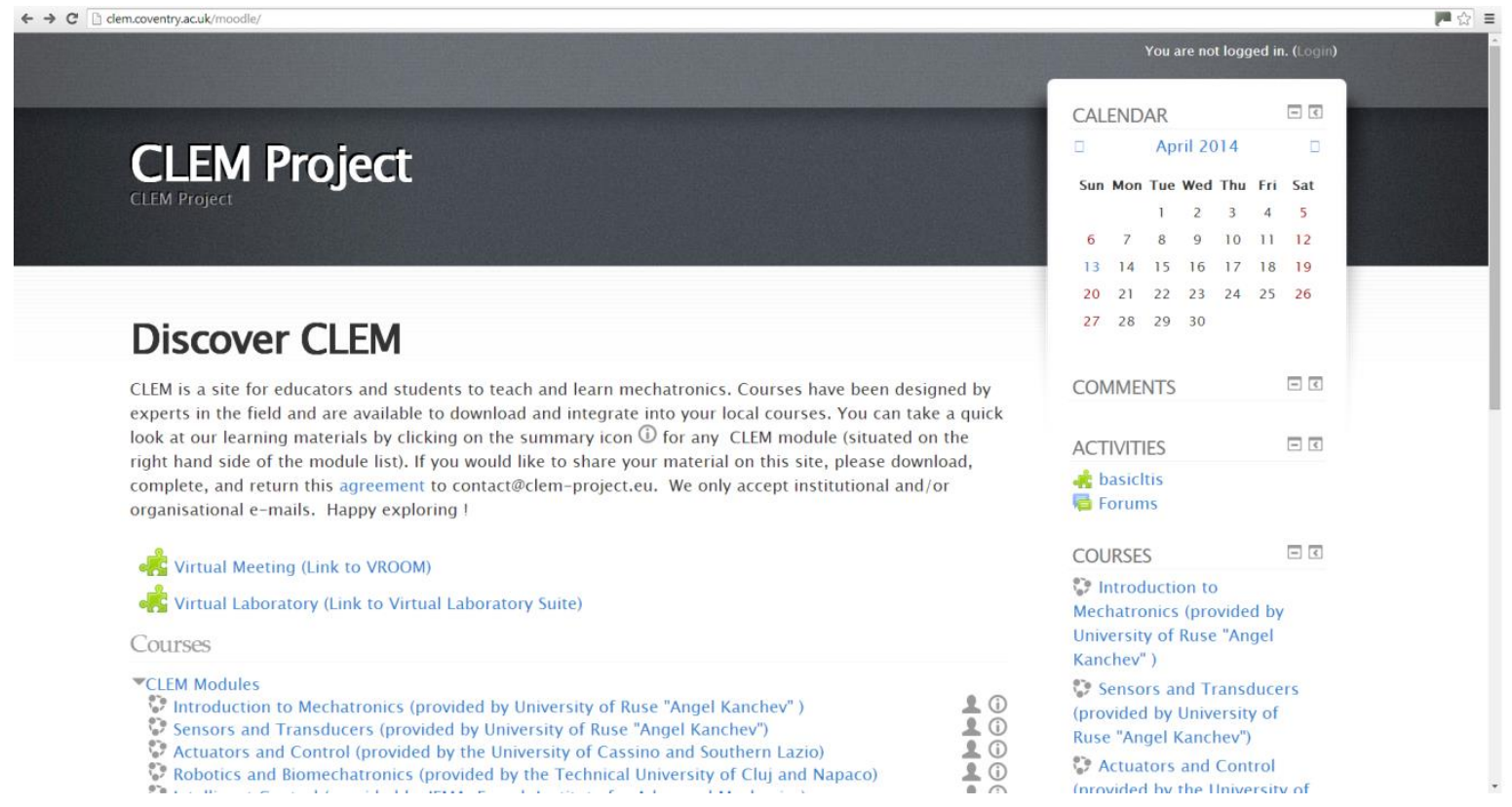

Fig. 3. Example of part of a static module on cloud technology

The modules provided are intended as examples (see Fig. 4). The expectation is that when the ecosystem is established and running well, there will be many and varied static learning materials available.

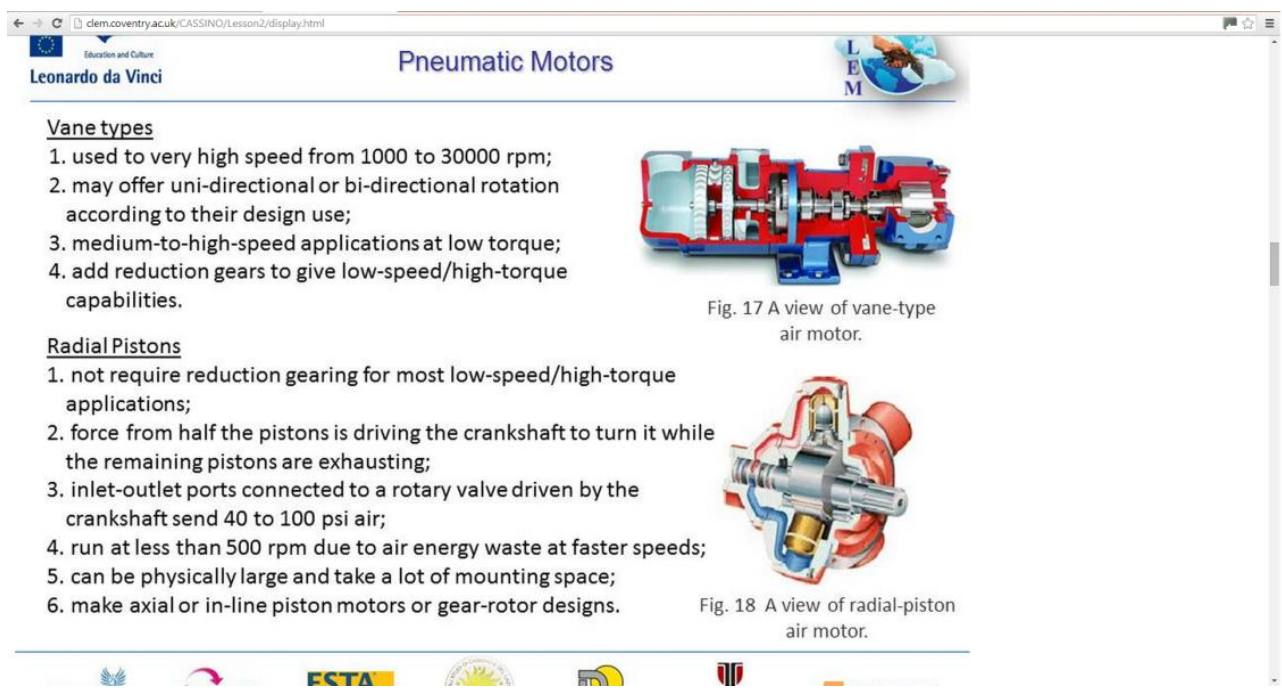

Fig. 4. Example of part of a static module on cloud technology

\subsection{Dynamic Remote Laboratories}

Our approach extends the concept of the remote laboratory of the DSCM group at HOU [16] in terms of examples, architecture and scalability. A crucial CLEM principle is the community aspect and the idea of multiple laboratories which can be booked through a single system. We have created 
dynamic online laboratories in our partner institutions. The architecture of our online remote laboratories consists of the CLEM server linked to remote servers, some of which are Raspberry Pis. The remote severs are linked to an Arduino microcontroller, which in turn controls devices such as CNC machines, LED switches and Servo motors.

Users of the remote laboratories can book a slot though the CLEM scheduling system (see Fig. 5). Since there are many remote laboratories linked in, if a slot is not available at one, the user can be directed to another. When a user has a slot in a remote laboratory, he/she can interact which the controllable devices by loading up Arduino programming code. Some ready-made examples have been provided so the learner can start by using and altering code that is already there (see Fig. 6). The users can also create their code or modify and save them in the repository for public or private use in the future. Currently the control of device is through the microcontroller, so the programming language needs to pass the microcontroller's complier and processors. The advantage of this approach is that it increases the portability of the code in the repository.

The webcam provides live video stream of the device operation status.

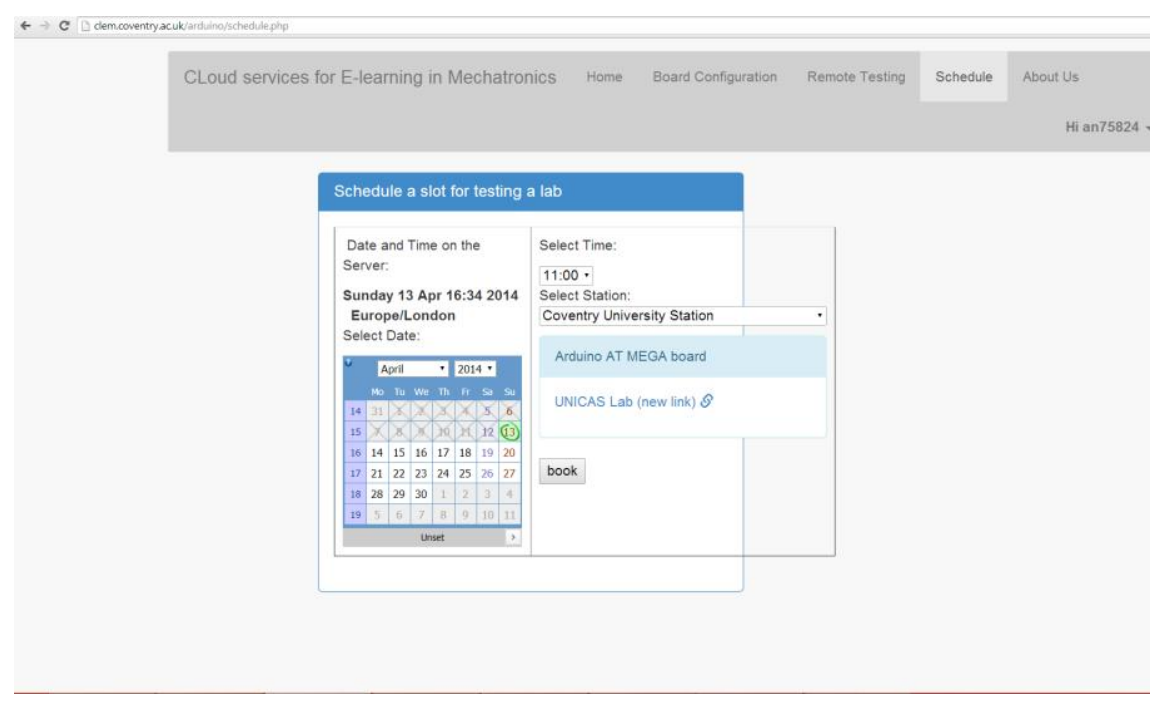

Fig. 5. The Virtual Laboratory Booking System 


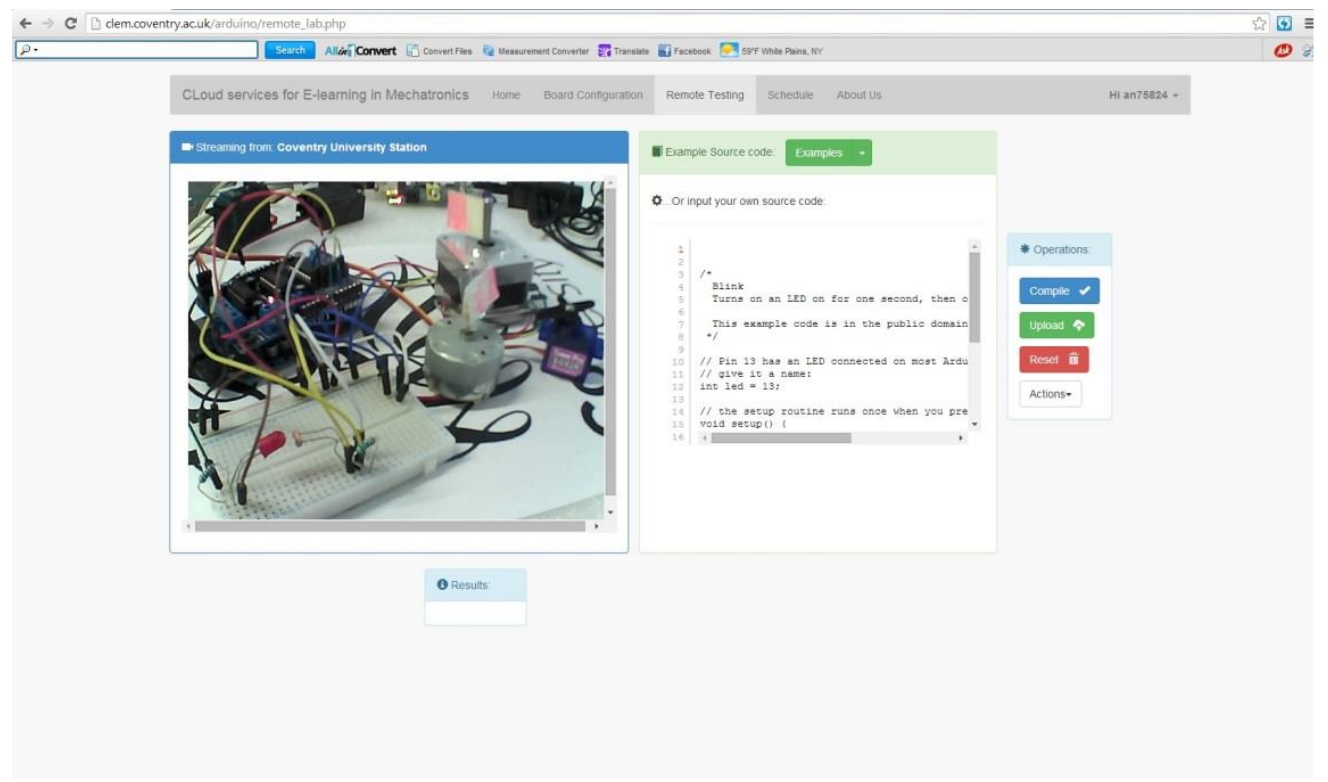

Fig. 6. Screenshot from a session using the remote laboratory.

\subsection{Virtual Meeting Room and Expert Channel, CLEM ROOM}

The rationale behind the CLEM project is to develop and transfer knowledge about mechatronics to VET teachers and trainers in an efficient way. Collaboration is at the heart of this idea. We therefore considered it important to provide, within the platform, specialised tools for collaboration to encourage cross-fertilization of ideas and innovation. We decided on two useful methods for sharing and exchange of knowledge: an expert channel; and a virtual meeting system. The expert channel will allow experts to register and will allow users to pose questions to experts. The virtual meeting room allows registered users to set up and conduct meetings between themselves to discuss items about mechatronics teaching and learning. The virtual meeting system provides support for structured meetings with agendas, items, invitees, item leaders, polls and document upload. Providing this structure makes the meeting run more efficiently. We have called the virtual meeting room CLEM ROOM.

CLEM ROOM, which is part of the resources provided by the CLEM, sits on the CLEM platform alongside the static and dynamic resources. CLEM ROOM has three main functional areas: Expert Channel; Meeting Space; Message Space. Teachers can communicate with experts and each other through these facilities. Fig. 7 provides an overview of the CLEM ROOM structure and Fig. 8 provides a screen shot of part of this service. 


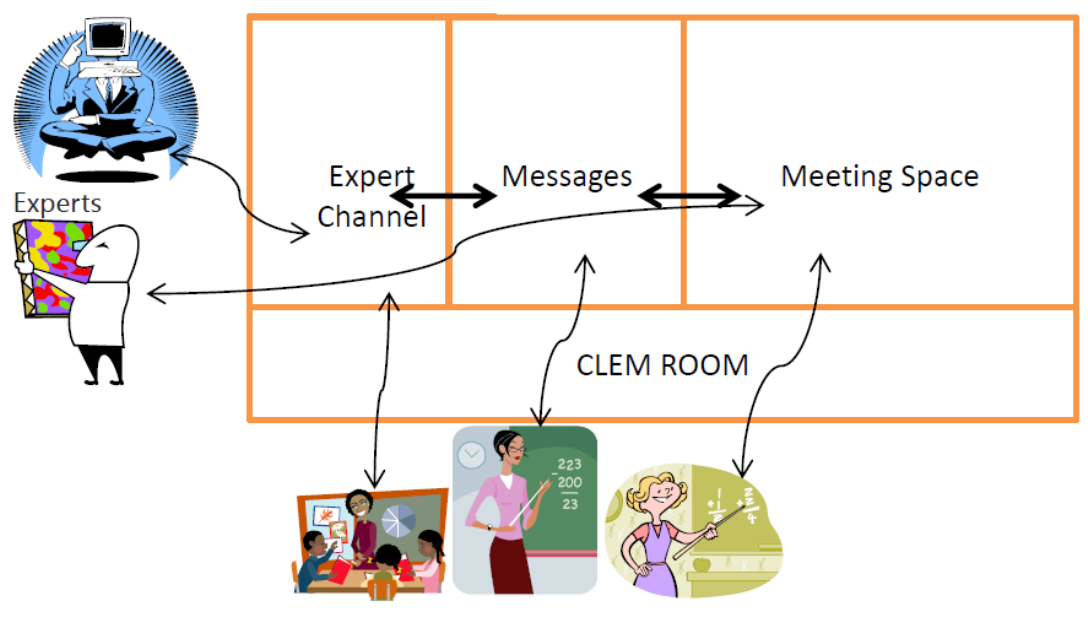

Teachers

Fig. 7 Overview of CLEM ROOM
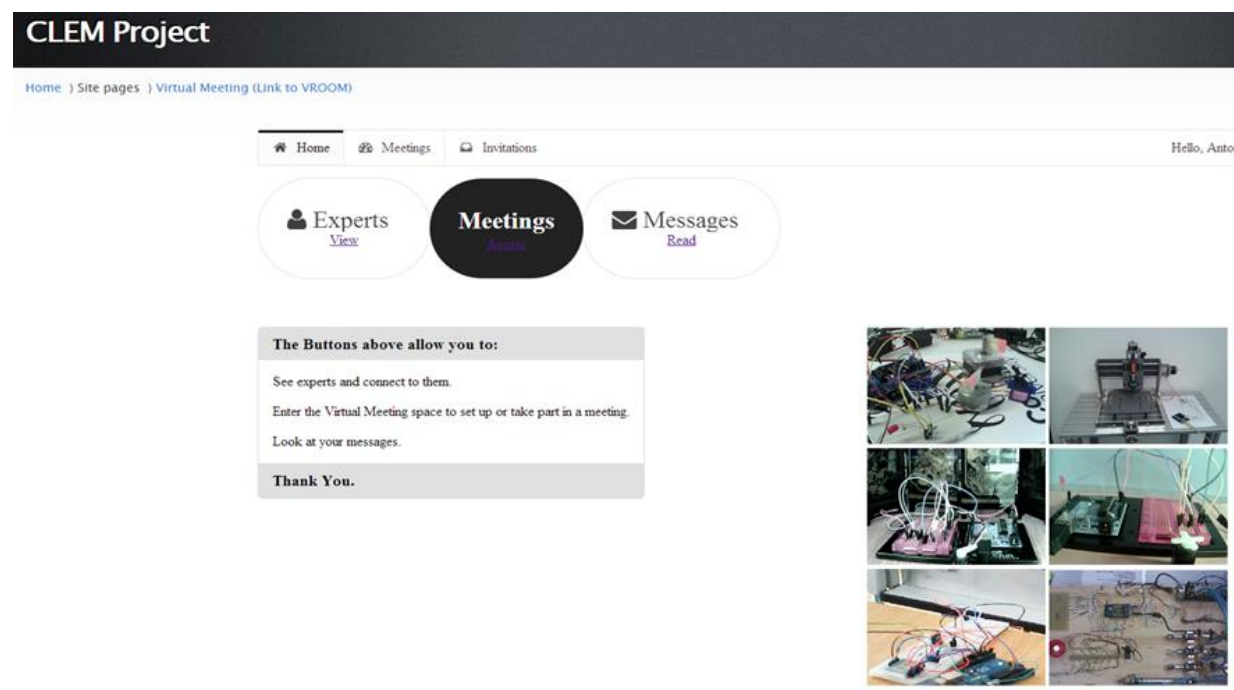

Fig. 8 Screen shot of front page of CLEM ROOM 


\section{Evaluation of CLEM as a Cloud Service}

In this section, we will review key features and functions of cloud computing and how these are utilized in CLEM.

\subsection{Cloud Characteristics and CLEM}

Cloud computing is a way of delivering computing resources over the Internet [30]. A pool of hardware or software resources can be gathered and presented as one virtual resource which is accessible to thin or thick clients in a client/server architecture. CLEM offers similar functions, as it intends to group different hard and soft learning resources for mechatronics at one virtual point which can be employed by the e-learners and trainers. Cloud computing is a domain independent platform, whereas CLEM has specific interests in mechatronic and related disciplines. The definition of the resources in CLEM is different from cloud computing. The hard resources in the context do not only include computers, memory and storage, but also physical artifacts such as CNC machines, motors, robots and $3 \mathrm{D}$ printers. The soft resources are artifacts like multimedia which can be stored in electronic form such as video clips, animation, programs, and slides.

National Institute of Standards and Terminology (NIST) [31] has further defined cloud computing by giving the following five characteristics. The way in which these characteristics are manifest in CLEM is described.

- On-demand self-service: A service provider is able to provide computational resources to clients /consumers according to their demands without requiring human interaction. CLEM to delivers e-learning resources to teachers and learners based on their demands. Teachers and learners can reserve the required resources through a booking system. For hard resources, the scheduling service in the system can automatically allocate and lock the resources to the client who booked. For the soft resources, instances can be made and the required memory to store the states can be allocated.

- Broad network access: The resources and capabilities in the cloud can be made accessible or available over the network and accessed by heterogeneous thin or thick client devices (e.g. mobile phones, laptops, and tablets). CLEM is accessible anytime and anywhere by any device.

- Resource pooling: A cloud provider is able to gather heterogeneous computing resources into a pool to serve multiple consumers concurrently. It is able to dynamically allocate and reallocate physical and soft resources (e.g. storage, processing, memory, network bandwidth, and virtual machines) to the consumers based on their demands. The CLEM platform is designed to support multiple learners and trainers by collecting different soft resources in a pool, so a multiple-tenant model can be used to manage their resources and states, but not the hard resources. The physical artefacts will be located in different places and managed by their local owners. The resource 
owners need to register themselves as members of the community to share their resources. The CLEM platform is a point to gather these resources and make them available to the users. CLEM has no ownership of these resources which is different from the existing cloud systems.

- Rapid elasticity: The provision of resources and capabilities rapidly can be scaled up or down according to the demand, so cloud is elastic and on-demand computing paradigm. CLEM is an elastic platform, as it has a collection of resources contributed by the community which can meet the demands by involving more resources provided by community members or releasing them according to the demands.

- Measured service: A cloud system provides on-demand services with finance implications which are needed to measure and meter the resource provided and consumed in order to provide transparency for both the provider and consumer of the utilized service systems. The CLEM platform is a free service for the trainers in the first instance. It provides a scheduling system to optimise its resources, so the trainers and learners can book their intended resource usages in advance in terms of time and size.

\subsection{Cloud Computing Service Model}

Cloud services, resources, or capabilities are delivered by three well-known cloud service models and these are Infrastructure as a Service (IaaS), Platform as a Service (PaaS) and Software as a Service (SaaS) [32, 33]. In this section, services and functions provided in CLEM will be described in terms of these aspects. Fig. 9 shows the CLEM service model.

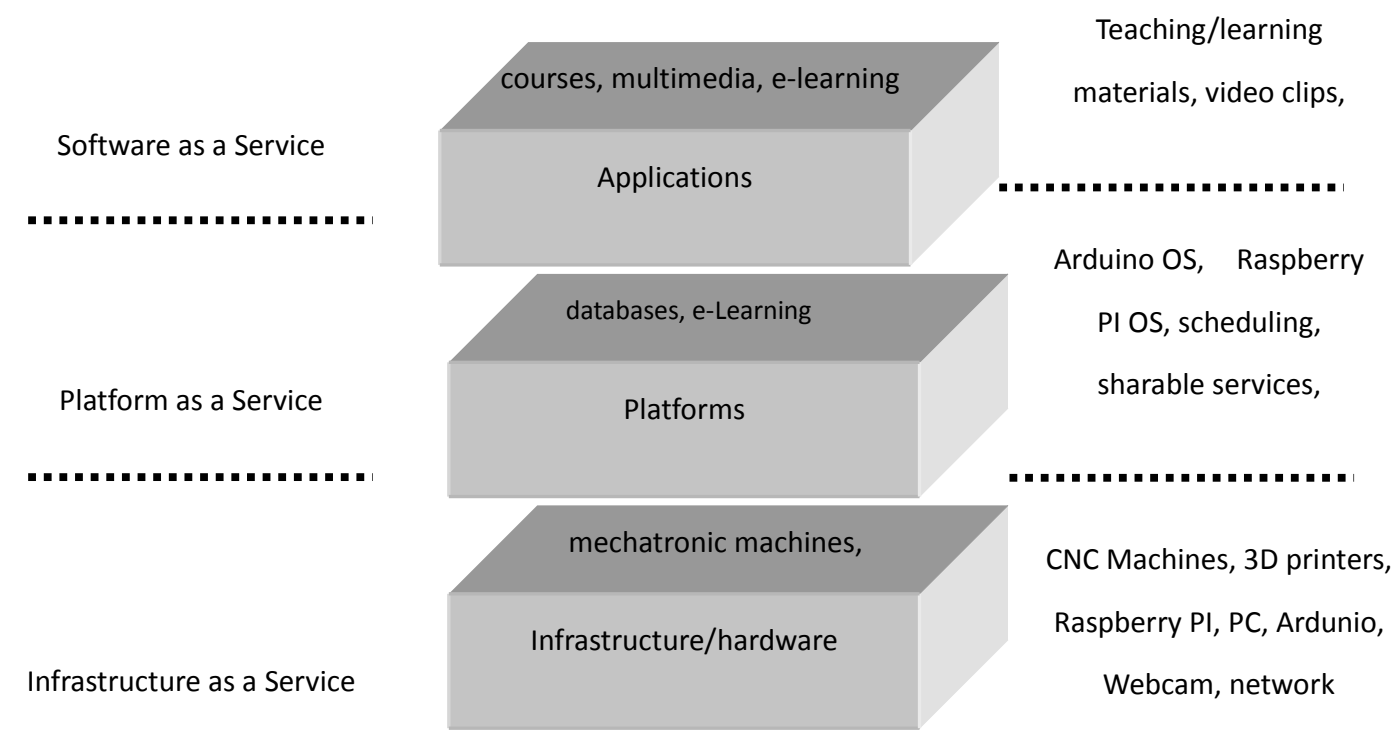

Fig. 9 CLEM Service Model 


\subsubsection{Infrastructure as a Service}

The IaaS model pulls together hardware, such as servers, storage, networks, and the data centre to form services to meet users' demands. The infrastructures can be configured and partitioned into multiple virtual machines on which the users can deploy and run their applications. The underlying cloud infrastructure is managed and controlled by the providers. The user can request when and how many resources are needed, but it is the provider which must release and manage the needed resources. CLEM is a community based cloud system, as the infrastructures such as mechatronic devices are provided by the member of community which can be located in a distributed environment. These devices are controlled and managed by their local owners, but they can be centrally scheduled and allocated when they are not in use for their local owners. These machines are virtually collected and configured in a pool, so the users can make requests to consume the resources through one point. The service provider needs to make their resources available to others by registering themselves to the CLEM platform which can openly access these machines.

\subsubsection{Platform as a Service}

The PaaS model is a facility that enables the developers to consume the resources in IaaS and deploy their applications onto a virtualised cloud platform. PaaS includes necessary elements that allow the software to run and deploy such as operating systems, databases, development tools, source control repository, and runtime environments and other middleware. The developers can just focus on the code running it. CLEM provides a set of services to alleviate the differences in machines and devices. It also supports various operating systems, databases, source code management tools, and teaching material repository management tools. The resource contributors can easily deploy their resources to the CLEM platform. The trainers can concentrate on their development of teaching materials or developing their code for the learners.

However, the machines have their own interfaces and operating commands. So CLEM needs a PaaS level to bridge their differences or provide common interfaces that allow trainers to work in a consistent environment, with high-level code and tools, without worrying too much about specialised machine code. The platform can manage the underlying infrastructures and support different operating systems and runtime environments for e-learning materials and control programs. The trainers can place and retrieve teaching materials in and from the storage devices without knowing detailed read and write commands. 


\subsubsection{Software as a Service}

The SaaS model enables network-based applications to be scalable, configurable and centrally manageable. The service delivery model supported by SaaS is a one-to-many model based on instances and a multi-tenant architecture rather than the traditional one-to-one model. The application has centralized features, multiple instances and update propagation from central copy to replicated instances. A single version of the application can be configured with services such as hardware, network and operating system to be employed by all tenants. Each tenant works with a customized virtual application. To support scalability, the application is installed on multiple machines (called horizontal scaling). CLEM is a multi-tenant architecture as exercise codes and teaching materials are stored in a centralised database that can be instantiated at runtime and changed to meet their requirements at design time. Tenants are able to select code from the centralised database, update them or write new codes and then choose whether to publish these is the centralized database or hold separately in their own tenanted area. The platform can support multiple programs, courses and exercises that manage their states disparately within the system. The required hardware such as mechatronic machines can be specified and software instances can be run on them. Each remote resource or a remote laboratory for a collection of resources is associated with a physical server machine including a set of components that are able to compile, execute and upload the programs specified by users to a microcontroller to consume the resources and manage their lifecycle.

In embracing the cloud ideal, CLEM has another important difference from much of the existing work. In sharing its method and providing other user support, CLEM will play an important part in promoting the approach. We use web-based cloud services to deliver both the static and dynamic material. Additionally, we provide services to enhance cooperation and stimulate innovation. The learners can easily use the teaching materials and carry out experiments anytime and anywhere. They can get instant feedback about their tests and experiments. The learners can discuss their learning experiences with others and get advice from the experts when needed.

\subsection{Specifications of the CLEM Service Model}

This section will offer more description on the concrete functions and elements provided by CLEM in three service layers.

\subsubsection{CLEM IaaS Layer}

The bottom layer of the architecture is IaaS which consists of physical hardware infrastructures such as servers, mechatronic devices (e.g. CNC machines and 3D printers), network and microcontrollers (e.g. Arduino). These resources can be dedicated or non-dedicated to CLEM, but they are distributed and normally controlled by their local administrators. For non-dedicated devices, the administrator can explicitly publish the timetable through CLEM to show when the resources can be shared with the public. Each mechatronic device is driven by a microcontroller and the microcontroller is connected to 
a local server. Each microcontroller can communicate with multiple devices via wire or wireless connections. A centralised and dedicated server is designed to host essential databases and software services which are responsible for communicating with the users and other servers.

Each device has its own unique ID and their associated input/output ports in the microcontroller, the internal IP address is used as ID for each microcontroller and each remote or local server needs a public IP address as an identifier or a channel for communication. The information is recorded in the central server when a device is registered as a CLEM shareable resource which can be configured with a set of readymade services.

\subsubsection{CLEM PaaS Layer}

The CLEM platform consists of a database system, interactive software management, a Moodle e-learning framework, a scheduling and booking service and connection to remote laboratories. All of these services are accommodated in the central server. The database system stores the user's profiles to control the access to the sharable resources. It also records device IDs and related information, so it has information about what devices exist in CLEM and their status. The interactive software management allows the users to input the sources and compile and upload them to the microcontroller in order to control the devices. The function is realised through the cooperation among the central server, remote laboratory server and microcontroller. The central service provides facilities for users to select the designated devices, input their code and observe the outcomes. Once it receives the "submit" command, it passes the code to the designated microcontroller which will compile the code, upload it to the memory for execution and return the outcome back to the central server for the user. Because of concerns of security and resource management, the user, in this architecture, does not directly communicate with the devices in the remote laboratory. The advantage of this approach is to prevent the inappropriate code from being uploaded to the microcontroller since the server acts as a filter and the code needs to pass the compiler and authentication.

Apart from the physical resources in remote laboratories, CLEM also provides soft teaching materials about mechatronics with different formats including PowerPoint documents, video clips, and image files. In order for the teachers or trainers to use them easily, they are stored in a database system and managed by the Moodle framework. The facility provided in Moodle allows them to create their own teaching materials from scratch or copy from existing teaching materials in the repository and save these as their local copies.

\subsubsection{CLEM SaaS Layer}

The top layer is SaaS which accommodates various data and applications. In CLEM, it hosts teaching materials for learners and trainers. It also includes exemplar courses with modules and each module contains a number of lessons and laboratory exercises. These data are generally shared among all the trainers or tenants on a physical server, but each trainer/tenant has its own set of course materials that are logically separated from the course materials that belong to other tenants. The trainer can select the desired teaching materials from the pool and compile them to a tailored course. Each tenant has his/her 
own set of courses that are grouped into a structure created specifically by the tenant. The system can house multiple tenants in the same database with different addresses or directories with proper security measurement to prevent any tenant from accessing other tenants' data accidentally or maliciously.

Multiple learners can access the same teaching materials and exercises with different instances, so the state of their learning can be stored in discrete isolated memory. The learners can test their program on physical sharable resources (i.e. mechatronic devices) by uploading them to the microcontroller. Only one device at one time can be used by tenant but a laboratory including one or more servers can have multiple microcontrollers, so it is accessible to multiple tenants. Each server in the remote laboratory has at least one webcam installation to show the status of devices in real-time, so the learners can gain instant feedback about the uploaded programs to the microcontroller. CLEM can only support multiple-tenants to a degree in IaaS due to the characteristics of physical sharable resources, but it supports multiple-tenants in PaaS and SaaS layers.

The mechatronic resources in CLEM are heterogeneous and located in scattered places mainly relying on the volunteering contribution from the mechatronic community. CLEM provides a set of services and steps to resource providers for setting up remote laboratories and making their devices sharable. Trainers have to register themselves with CLEM in order to create new courses and to add new teaching materials. After their successful registration, they can enrol their learners to the system and book the resources for them to do exercises. Most devices and laboratories are open 24/7 to users, apart from $\mathrm{CNC}$ devices and 3D printers which require placement of the raw materials to the machines such as wood, polyester, and plastic powder to drill or cut according to the given specifications. The other reason for the machines not being available all the time is concern about health and safety. Anyone, however, can book sharable devices for a period of time to test out their programs as long as they have registered with the CLEM and the machines are available.

\section{User Evaluation and Survey Result Analysis}

The focus of the user evaluation of the CLEM platform is to measure its usability and effectiveness on the teachers' or trainers' teaching styles and students' learning outcomes. Therefore, instead of measuring the system performance, surveys were carried out on 170 trainers or potential trainers in various dissemination events, taking place in Bulgaria, France, Germany, Italy, Romania, and UK to understand the effectiveness of the CLEM.

The questionnaires were handed out to the participants to complete after a session of CLEM demonstration or tutorial has been held to show how to set up a new course and use mechatronic devices in the remote labs. These trainers with different subject backgrounds and teaching experiences have inconsistent learning curves, but most of them completed the task in time. The questionnaire contained 10 questions. The response frame to the first 9 questions was organised as a five-level Likert item. For instance for the question, "How easy is it to obtain the learning resources you need from Internet?", the response frame was structured as shown below.

○ Extremely easy

○ Very easy 


$$
\begin{array}{cl}
\circ & \text { Moderately easy } \\
\circ & \text { Slightly easy } \\
\circ & \text { Not at all easy }
\end{array}
$$

In our analysis we consider the top two responses of the frame to be positive, the bottom two negative and the middle answer neutral. The last question of the questionnaire was open and offered participants opportunity to make free-style comments about the CLEM system.

The questionnaire starts with exploring how well participants know mechatronics, the cloud learning environment, Moodle and the effectiveness of teaching at their institutions and ease of Internet use for obtaining learning resources. We found that $41 \%$ knew mechatronics extremely or quite well but $29 \%$ only know the topic area mildly well or not at all well. 29\% of participants knew Moodle either extremely well or quite well but $50 \%$ only knew it mildly well or not at all well. Around $72 \%$ of participants agreed the teaching in their institutes is extremely effective but $9 \%$ found the teaching only slightly or not at all effective. In response to the question "How easy is it to obtain the learning resources you need from Internet?", 69\% of participants answered positively in that they found it extremely easy or very easy but $10 \%$ answered negatively that they found it not at all or only slightly easy.

Then questionnaire then explored more specific questions concerning the tool presented. Positive answers were given by $65 \%$ to the question "How well would the tool you have seen contribute to meeting the learning needs of your students?" but $14 \%$ answered negatively as not at all well or slightly well (see Fig. 10)

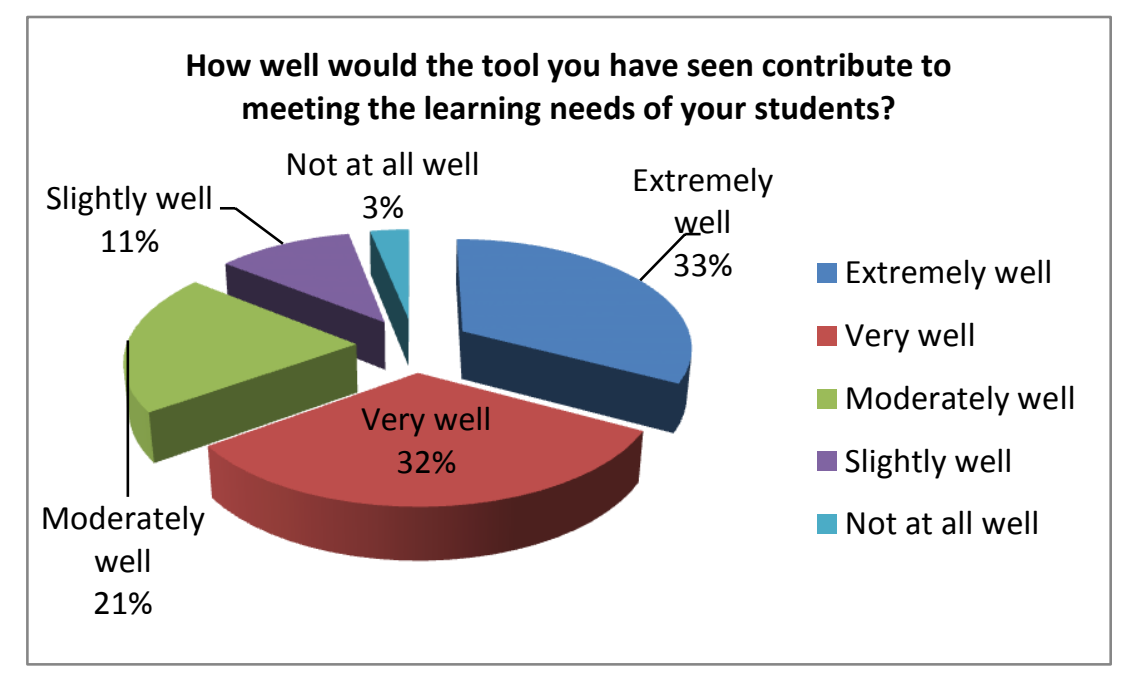

Fig. 10. CLEM platform: Match to students' learning needs

Fig. 11 shows that $70 \%$ of participants found the tools provided in CLEM are extremely or very helpful while $11 \%$ found them only slightly or not helpful. Fig. 12 shows that $67 \%$ of participants think the CLEM is extremely or very easy to use but $11 \%$ of them think slightly or not easy at all to use. 


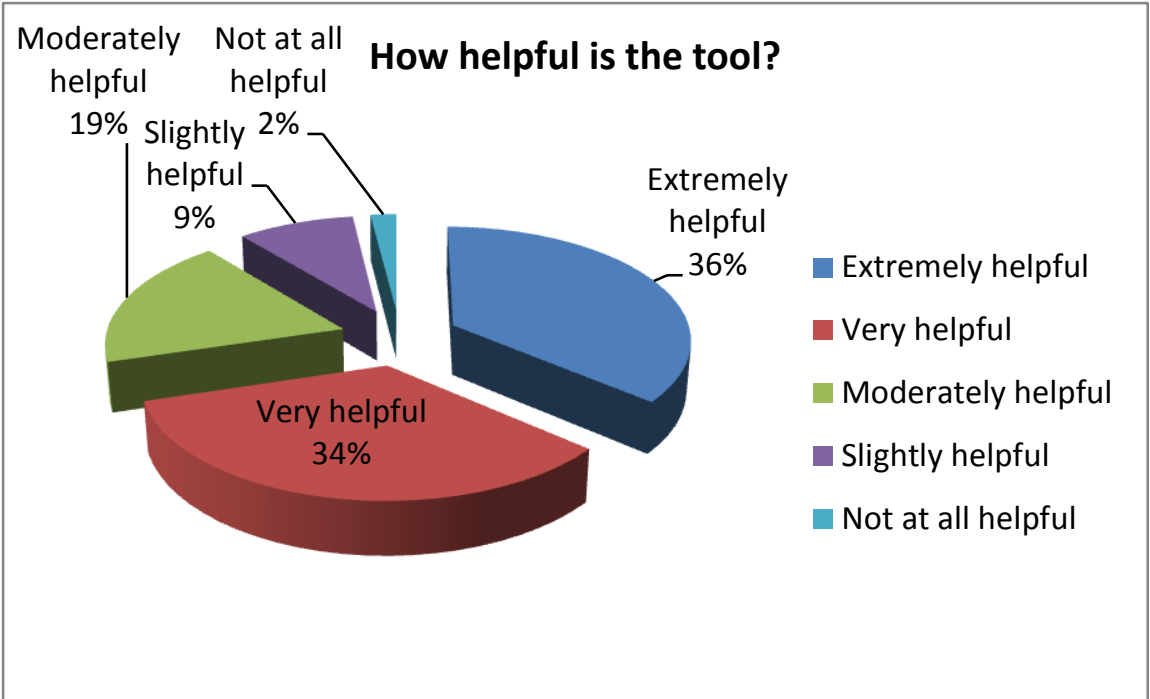

Fig. 11. CLEM platform: Helpfulness

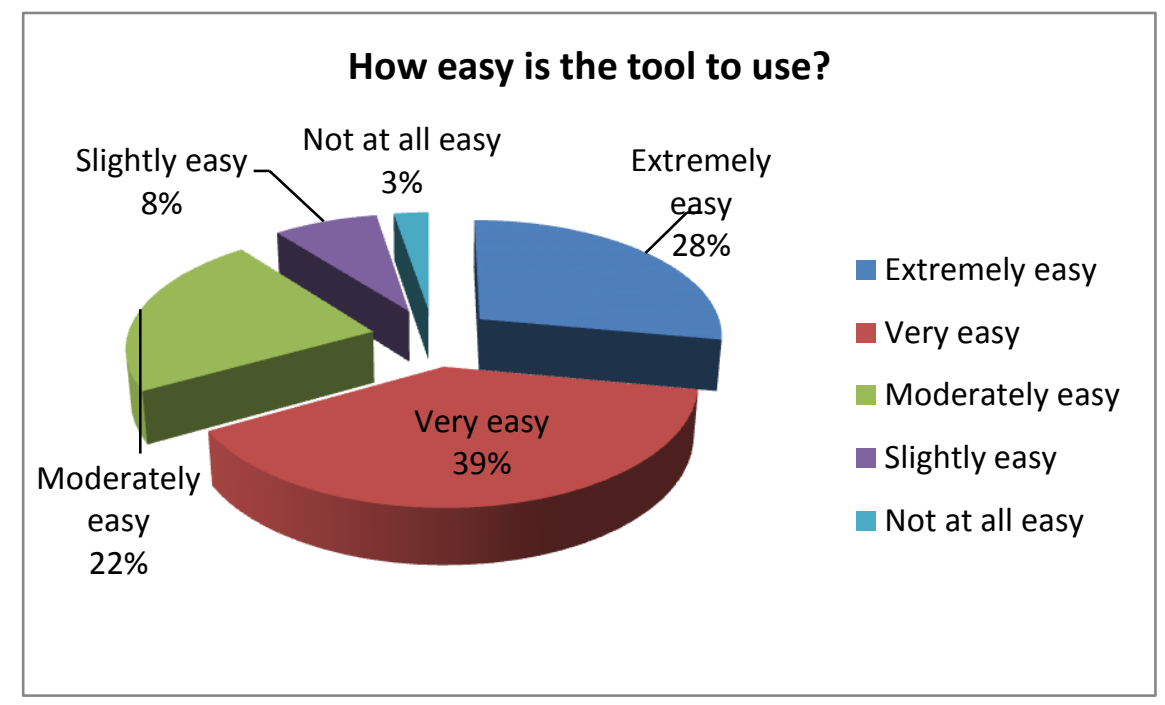

Fig. 12. CLEM platform ease of use

Fig. 13 shows the participants' opinions for the question "How well do the activities offered from this project match your student's interests?" It shows that $20 \%$ of respondents agree that CLEM would match their students' interest while $48 \%$ thought it would only match mildly well or not well at all. Fig. 14 shows the feedback from the participants on the question "How well does the cloud computing learning/teaching style match your learning or teaching style?" $47 \%$ of teachers think it matches extremely or quite well, and $14 \%$ them only found it matched mildly well or not well at all. 


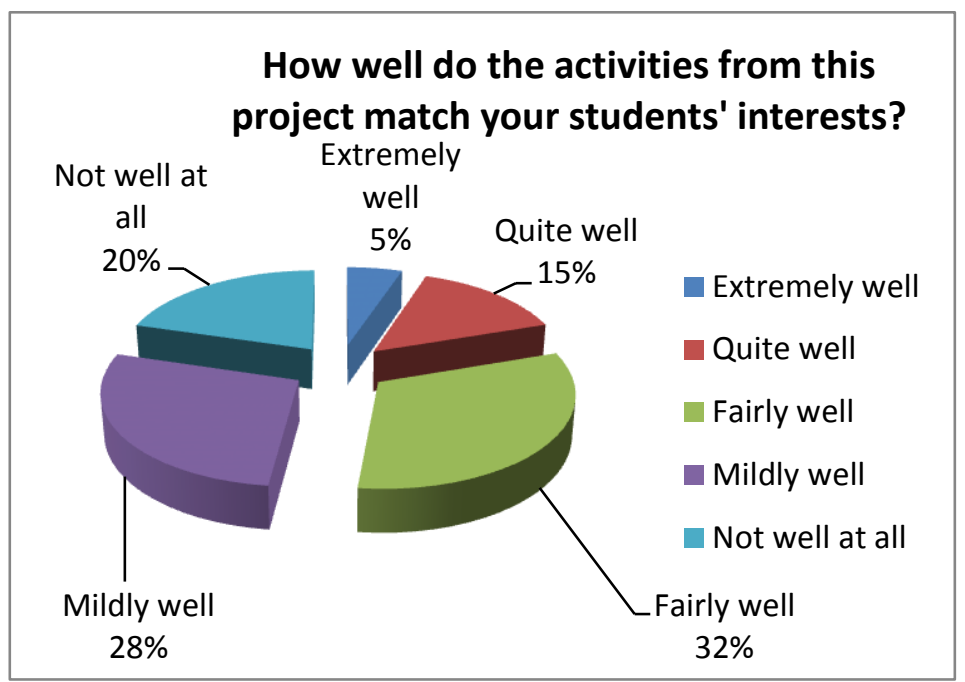

Fig. 13. CLEM platform: Match to student interests

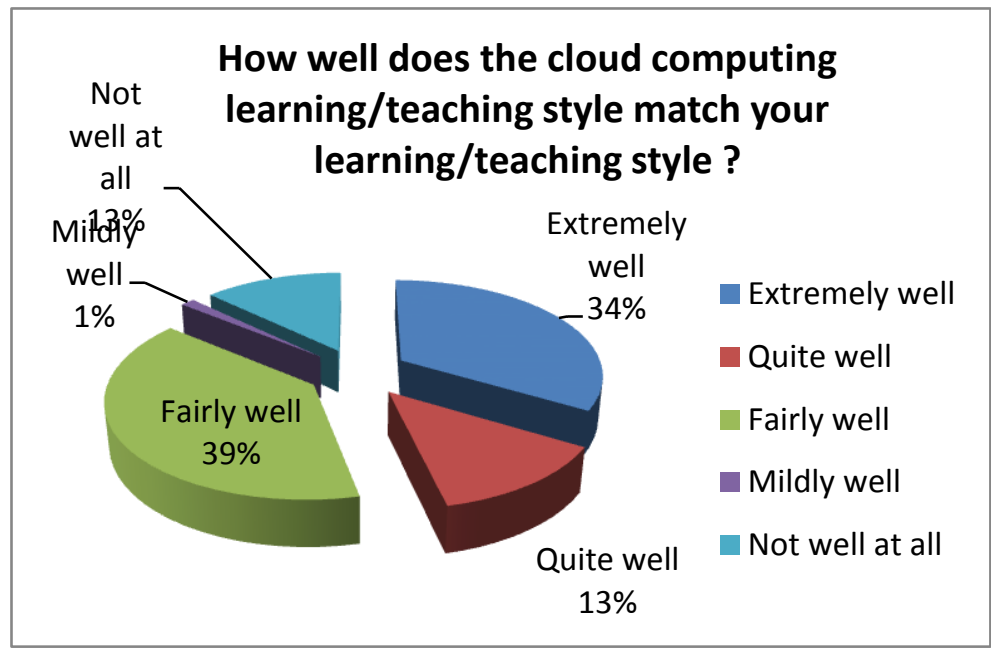

Fig. 14. CLEM platform: Match to learning and teaching style

There is a disparity between the results for the questions on relevance to student learning needs, helpfulness of tool and ease of use on the one hand (average - 69\% positive, $19 \%$ neutral, $12 \%$ negative) and matching student interest and current teaching style on the other (average - 35\% positive , $45 \%$ neutral, 20\% negative). This indicates that whilst the teachers see the benefits of the tool and the need for students to learn through this method, at the moment, the approach and content is not matching their current style nor is it matching student interest particularly well. This observation relates to the finding from an earlier part of the questionnaire that only $41 \%$ of the teachers knew mechatronics extremely or quite well and only 29\% knew Moodle extremely or quite well. The finding supports our premise of the need to widen the knowledgebase in mechatronics and cloud e-learning through provision of appropriate support methods. It also supports our proposition that CLEM is offering a new style of teaching. The teachers recognize the relevance of the CLEM platform to student learning needs as well as its ease of use and helpfulness. This supports our idea that new community and cloud based tools are needed for VET and will be appreciated. However, the concept of cloud computing may not be easy for some 
teachers to adopt. This could be due to their lack of familiarity with cloud technologies and also availability of access resources at their teaching institution. We can conclude that CLEM has potential to be an effective platform for most participants, but current curricula and teaching styles will need to change so that trainers and learners can extract the highest benefit the cloud based platform and the current advances of e-learning.

\section{Cloud based E-learning approaches}

This section reviews the latest developments in cloud based e-learning approaches. Cloud computing technologies offering numerous advantages have attracted much attention and investment from industry and academy including the e-learning research community. A number of researchers $[34,35,36]$ have analysed the benefits to e-learning that can be gained by introducing cloud computing technologies such as low cost, improved performance, increased reliability, better security and instant software update [37]. Fernandez et al. [38] proposed the concept of "E-Learning in the Cloud" as Education Software-as-a-Service which tries to exploit the values of cloud computing to education. CloudIA [39] is a framework designed for the students to create their own Java servlet environment for experimentation. The focus of the work is to efficiently support on-demand virtual resources creation and management. It aims to release the students from worrying about the underlying supporting environment to concentrate on achieving their main learning objectives.

Cloud computing can improve e-learning processes in virtual e-universities Error! Reference

source not found. with different operation models and highly interoperable IT services to increase service reliability and reduction of cost. The BlueSky Error! Reference source not found. architecture contains a number of cloud-based e-learning services to provide efficient resource management by being able to pre-schedule and pre-allocate resources for the high-demand applications prior to requests. As a solution to the issue of limited scalability in tradition e-learning systems, Phankokkruad [42] proposed a cloud computing architecture for e-learning which consists of three layers: Infrastructure (cloud database, resources); platform (content management, assessment management) and application (client interface services).

Some researchers have investigated cloud technology to support informal learning. García-Peñalvo et al. [43] presented TRAILER which is software that can be used to tag interactions a user may have with various informal cloud-based systems such as social networking systems and which can contribute to a base of learning experiences. The main idea behind this work is to bridge informal and formal learning to the benefit of individuals and organisations and to create a record of learning. Zurita, Balonian and Frez [44] focus on situated learning which is frequently associated with informal learning or learning outside the classroom. They propose a software architecture schema which can be used as a basis for integrating existing cloud services into new applications to support such learning activities. Geographical information is highly relevant and this can be combined with other cloud services such as micro blogging to create a collaborative learning environment. The research described in this paragraph has some similarities to ours in that communities of learning are developed and integration of services 
is paramount. However our focus is not on the geographical, mobile or informal aspect but on remote actualization in the context of cloud based communities of learning.

MOOCs (Massive online open courses) are also becoming popular [45]. These are courses provided by universities which are open to the public. The development started in prestigious universities in the United States and has now been taken up by top universities elsewhere. The use of Amazon Web Services (AWS) to support a MOOC has been explored and has been found satisfactory [46]. MOOCs differ from our approach in that they do not incorporate remote laboratories or collaborative communities of learning.

Many analyses on the advantages and disadvantages of cloud computing and e-learning frameworks have been found in the literature, but they lack detailed descriptions on the activity of modelling e-learning and cloud computing. Only a few researchers reported the results of their implemented cloud-based e-learning system, e.g. [42, 46]. Detailed analyses of effectiveness of e-learning cloud computing with real case studies have not been found. It is therefore difficult at this stage to evaluate the benefits of cloud computing on e-learning. In addition, there is no report about bringing in remote laboratories with physical machines and resources to the cloud to support the trainers and learners in e-learning. The proposed CLEM is, to our knowledge, the first system and platform which utilises cloud computing to create a community-based, dynamic e-learning system.

\section{Conclusion}

The CLEM project has established a cloud-based ecosystem for e-learning, resource-sharing and support for mechatronic vocational education teachers and learners. CLEM is a platform that allows large number of distributed mechatronic devices to become sharable and to be used for e-learning. The platform, based on the concept of cloud computing, enables isolated resources such as CNC machines, $3 \mathrm{D}$ printers, and stepper motors to be linked to electronic learning materials, administered through the cloud and consumed by the users remotely. The learners, teachers and trainers can book these resources through a scheduling system and access them via a web interface.

CLEM is different from other cloud computing systems, as computational cloud is built upon homogeneous computational resources such as computing, storage and networking. CLEM, a proprietary platform, is specially tailored to gather heterogeneous and distributed mechatronic devices in a common pool. The resources in CLEM are not as transferable as computational resources, due to the properties of mechatronic devices and their operation such as physical facets, non-standard control interfaces, human attention required for health and safety, irreplaceable at runtime, prone to disruptions, materials placement needed and manually positioning coordinates of machines. Due to these considerations, CLEM does not adopt traditional cloud operating systems, but it has a resource management system and scheduling system to connect and manage distributed resources.

The approach we have taken hinges on providing an exemplar system and method that others can add to or replicate. Current feedback shows that around $70 \%$ of participants in our training sessions have 
agreed that the CLEM cloud computing platform can bring positive influences or help to their teaching or students' learning. Given that our findings also show that CLEM embraces a new method of teaching, the parameters of which may need a little time for full appreciation by trainers used to their own style, we feel this is an encouraging initial outcome.

Future work will involve development of further services for VET teachers and learners including additional tools for community engagement and material sharing as well as extended dissemination of the approach. The concept of service-oriented architecture [47, 48] will be exploited in system design and implementation for the next generation to increase system flexibility and scalability.

\section{ACKNOWLEDGEMENT}

The work presented in this paper is supported by the European Commission Leonardo Lifelong Learning Programme (Project Name: Cloud E-learning in Mechatronics Technology, Project Number: 518656-LLP-1-2011-1-UK-Leonardo-LMP). The authors are grateful for this support. The authors would also like to thank the Digital Systems and Media Computing (DSMC) laboratory of the Hellenic Open University for useful support regarding the development of the remote laboratories. Our thanks go to all our project partners for their contributions.

\section{REFERENCES}

[1] J. Gubbi, R. Buyya, S. Marusic, M. Palaniswami, Internet of Things (IoT): A vision, architectural elements, and future directions, Future Generation Computer Systems 29 (2013) 1645-1660.

[2] J. Cooper, A. James, (2009). Challenges for database management in the internet of things, IETE Technical Review, 26 (2009) 320-329.

[3] A. Rojko, H. D. Hercog, and K. Jezernik, Distance mechatronics and alternative technologies training for practicing engineers and technicians, in: Proc. 5th IEEE Intl. Conf. on e-Learning in Industrial Electronics (ICELIE), IEEE, 2011, pp. 64-69.

[4] D. Pop, D. G. Zutin, M. E. Auer, K. Henke, and H-D. Wuttke, An online lab to support a master program in remote engineering, in: First Workshop on Global Online Laboratory Consortium Remote Laboratories (GOLC), IEEE, 2011 pp. 1-6.

[5] I. G. Pop, Ioan G., and V. Mătieş, Transdisciplinary approach of the mechatronics in the knowledge based society, in: Mechatronics, Intech Open Access Publisher, Rijeka, 2011.

[6] CLEM, Cloud E-learning in Mechatronics Technology, CLEM project website, accessible at: www.clem-project.eu

[7] R. D. Garrison, E-learning in the 21st century: A framework for research and practice, Taylor \& Francis, 2011.

[8] Z. Nedic, J. Machotka, A.Nafalski, Remote laboratories versus virtual and real laboratories, in: 33rd Annual Conference on Frontiers in Education (FIE 2003), volume 1, IEEE, 2003, pp. T3E-1 - T3E-6.

[9] N. Ertugrul, Towards virtual laboratories: a survey of LabVIEW-based teaching/learning tools and future trends, Engineering Education, 16 (2000) 171-180. 
[10] P. Bisták, K. Žáková, Organising tele-experiments for control education, in: Proc. 11th Mediterranean Conf. on Control and Automation, 2003.

[11] C. Martin, R. Muñoz, A. Urquia, S. Dormido, A distance learning course on virtual-lab implementation for high school science teachers, in: Proc. 6th Intl. Conf. on Virtual University (VU’05), 2005.

[12] K. Zakova, M. Sedlak, Remote control of experiments via Matlab, Online Engineering (iJOE), 2 (2006).

[13] V. Zilka, P. Bisták, P. Kurcik, Hydraulic plant remote laboratory, Online Engineering (iJOE), 4 ( 2008).

[14] A. Rojko, D. Hercog, K.Jezernik, Realization and experience of professional mechatronics e-training, in: Proc. 3rd IEEE Intl. Conf. on E-Learning in Industrial Electronics (ICELIE'09), IEEE, 2009, pp. 151-156.

[15] D. Chaos, J. Chacón, J. A. Lopez-Orozco, S. Dormido, Virtual and remote robotic laboratory using EJS, MATLAB and LabVIEW, Sensors, 13 (2013) 2595-2612.

[16] DSMC, Open Remote Arduino Labs at HOU, Digital Systems and Media Computing (DSMC) laboratory, Hellenic Open University, accessible at: http://dsmc2.eap.gr/component/content/article/project/open-remote-arduino-labs-at-hou

[17] OU Open Science, OU Open Science project website, available at: http://www.open.ac.uk/researchprojects/open-science/

[18] GOLC, Global Online Laboratory Consortium, GOLC project website, available at: http://online-lab.org/

[19] T. Richter, Thomas, D. Boehringer, S. Jeschke, Lila: a european project on networked experiments, in: Automation, Communication and Cybernetics in Science and Engineering 2009/2010, Springer Berlin Heidelberg, 2011, pp. 307-317.

[20] LiLa, LiLa project website, available at:http://www.lila-project.org/about/presentation_neu/index.html

[21] iLABS, iLABS project website, available at: https://wikis.mit.edu/confluence/display/ILAB2/about+iLabs

[22] B. Dong, Bo, Q. Zheng, J. Yang, H. Li, M. Qiao, An e-learning ecosystem based on cloud computing infrastructure, in: Proc. 9th IEEE Intl. Conf. on Advanced Learning Technologies (ICALT), IEEE, 2009, pp. 125-127.

[23] P. Pocatilu, Paul, F.Alecu, M. Vetrici, Measuring the efficiency of cloud computing for e-learning systems, WSEAS Transactions on Computers, 9 (2010) 42 - 51.

[24] F. Doelitzscher, A. Sulistio, C. Reich, H. Kuijs, D.Wolf, Private cloud for collaboration and e-learning services: from IaaS to SaaS, Computing, 91 ( 2011) 23-42.

[25] H. Ma, Hui, Z. Zheng, F. Ye, S. Tong, The applied research of cloud computing in the construction of collaborative learning platform under e-learning environment, in: Proc. Intl. Conf. on System Science, Engineering Design and Manufacturing Informatization (ICSEM), volume 1, IEEE, 2010, pp. 190-192.

[26] R. Iqbal, A. James, A., R.Gatward, A framework for integration of CSCW, in: Proc. 7th Intl. Conf. on Computer Supported Cooperative Work in Design, IEEE, 2002, pp. 43-48.

[27] P. Thompson, A. James, A. Nanos, V-ROOM: Virtual meeting system trial， in: Proc. 17th Intl. Conf. on Computer Supported Cooperative Work in Design (CSCWD), IEEE, 2013, pp. 563-569.

[28] A. G. Nanos, A. E. James, A virtual meeting system for the new age, in: Proc. 10th Intl. Conf. on e-Business Engineering (ICEBE), IEEE, 2013, pp. 98-105.

[29] A. E. James, K. M. Chao, W. Li, A. Matei, A.G. Nanos, S.D. Stan, G. Figliolini, P. Rea, C. B. Bouzgarrou, D Bratanov, J. Cooper, A. Wenzel, J.V. Capelle, K. Strueckmeier, An ecosystem for e-learning in mechatronics: The CLEM project, in : Proc. 10th Intl. Conf. on e-Business Engineering, IEEE, 2013, pp. 62-69. 
[30] R. Buyya, C.S, Yeo, S. Venugopal, J. Broberg, I. Brandic, Cloud computing and emerging IT platforms: Vision, hype, and reality for delivering computing as the 5th utility, Future Generation Computer Systems, 25 (2009) 599-616.

[31] NIST, NIST Cloud Computing Program, available at: http://www.nist.gov/itl/cloud/

[32] O. Zhonghong, Z. Hao, J.K. Nurminen, A. Lukyanenko, H. Pan, V. Mazalov, A. Yla-Jaaski, Is the same instance type created equal? Exploiting heterogeneity of public clouds, IEEE Transactions on Cloud Computing, 1 (2013) 201-214.

[33] L. George, Developing software online with platform-as-a-service technology, IEEE Computer, 41 (2008) 13-15.

[34] A. Jain, S. Chawla, E-Learning in the cloud, Latest Research in Science and Technology, 2 (2012) 31-41.

[35] A. A. Tayeb, K. Alghatani, S.A. El Seoud, H. El-Sofany, The impact of cloud computing technologies in e-learning, Emerging Technologies in Learning (iJET), 8 (2013) 37-43.

[36] U. J. Bora, M. Ahmed, E-Learning using cloud computing, Science and Modern Engineering, 1 (2013) 9-13

[37] F. Karim, R. Goodwin, Using cloud computing in e-learning systems, Advanced Research in Computer Science \& Technology (IJARCST), 1 (2013) 65-69.

[38] A. Fernandez, D. Peralta, F. Herrera, J.M. Benttez, An overview of e-Learning in cloud computing, in: Workshop on Learning Technology for Education in Cloud (LTEC'12,) Springer Berlin Heidelberg, 2012, pp. 35-46.

[39] A. Sulistio, C. Reich, F Doelitzscher, Cloud infrastructure \& applications - CloudIA, in: M. G. Jaatun, G. Zhao, C. Rong, (Eds.), Cloud Computing, LNCS, vol. 5931, Springer Berlin Heidelberg, 2009, pp. 583-588.

[40] E. Zaharescu, Enhanced virtual e-Learning environments using cloud computing architectures, Computer Science Research and Application, 2 (2012) 31-41.

[41] B. Dong, Q. Zheng, M. Qiao, J. Shu, J. Yang, BlueSky cloud framework: An eLearning framework embracing cloud computing, in: M. G. Jaatun, G. Zhao, C. Rong, (Eds.), Cloud Computing, LNCS, vol. 5931, Springer Berlin Heidelberg, 2009, pp. 577-582.

[42] M. Phankkokruad, Implement of cloud computing for e-leaming system, in: Proc. Intl. Conf. on Computer \& Information Science (ICCIS), volume 1, IEEE, 2012, pp. 7-11.

[43] F. J.García-Peñalvo, M. Johnson, |G.R. Alves, M. Minović, M., M.A. Conde-González, Informal learning recognition through a cloud ecosystem. Future Generation Computer Systems, 32 (2014) 282-294.

[44] G. Zurita, N. Baloian, N., J.Frez, Using the cloud to develop applications supporting geo-collaborative Situated Learning. Future Generation Computer Systems, 34 (2014) 124-137.

[45] T.R. Liyanagunawardena, A. A. Adams, S.A. Williams, MOOCs: A systematic study of the published literature 2008-2012, The International Review of Research in Open and Distance Learning, 14 (2013) 202-227.

[46] N. Sonwalkar, The first adaptive MOOC: a case study on pedagogy framework and scalable cloud architecture - part I, in: MOOCs Forum, 1 (2013) 22-29, available at: http://online.liebertpub.com/doi/pdf/10.1089/mooc.2013.0007

[47] A. Immonen, D. Pakkala, A survey of methods and approaches for reliable dynamic service compositions, Service Oriented Computing and Applications, 8 (2014)129-158.

[48] K. Grolinger, M.A. M. Capretz, A. Cunha, S. Tazi, Integration of business process modeling and web services: a survey, Service Oriented Computing and Applications, 8 (2014)105-128. 